\title{
Molecular mechanism of parallel fiber-Purkinje cell synapse formation
}

\author{
Masayoshi Mishina ${ }^{1,2 *}$, Takeshi Uemura ${ }^{2}$, Misato Yasumura $^{2}$ and Tomoyuki Yoshida ${ }^{2}$ \\ Brain Science Laboratory, The Research Organization of Science and Technology, Ritsumeikan University, Shiga, Japan \\ ${ }^{2}$ Molecular Neurobiology and Pharmacology, Graduate School of Medicine, The University of Tokyo, Tokyo, Japan
}

\section{Edited by:}

Egidio D'Angelo, University of

Pavia, Italy

\section{Reviewed by:}

Yang Dan, University of California, Berkeley, USA

Graziella DiCristo, University

of Montreal, Canada

${ }^{*}$ Correspondence:

Masayoshi Mishina, Brain

Science Laboratory, The Research

Organization of Science and

Technology, Ritsumeikan

University, Nojihigashi 1-1-1,

Kusatsu, Shiga 525-8577, Japan.

e-mail:mmishina@fc.ritsumei.ac.jp
The cerebellum receives two excitatory afferents, the climbing fiber (CF) and the mossy fiber-parallel fiber (PF) pathway, both converging onto Purkinje cells (PCs) that are the sole neurons sending outputs from the cerebellar cortex. Glutamate receptor $\delta 2$ (GluR $\delta 2$ ) is expressed selectively in cerebellar PCs and localized exclusively at the PF-PC synapses. We found that a significant number of PC spines lack synaptic contacts with PF terminals and some of residual PF-PC synapses show mismatching between pre- and postsynaptic specializations in conventional and conditional GluR $\delta 2$ knockout mice. Studies with mutant mice revealed that in addition to PF-PC synapse formation, GluR $\delta 2$ is essential for synaptic plasticity, motor learning, and the restriction of CF territory. GluR $\delta 2$ regulates synapse formation through the amino-terminal domain, while the control of synaptic plasticity, motor learning, and CF territory is mediated through the carboxyl-terminal domain. Thus, GluR $\delta 2$ is the molecule that bridges synapse formation and motor learning. We found that the trans-synaptic interaction of postsynaptic GluR $\delta 2$ and presynaptic neurexins (NRXNs) through cerebellin 1 (Cbln1) mediates PF-PC synapse formation. The synaptogenic triad is composed of one molecule of tetrameric GluR $\delta 2$, two molecules of hexameric Cbln1 and four molecules of monomeric NRXN. Thus, GluR $\delta 2$ triggers synapse formation by clustering four NRXNs. These findings provide a molecular insight into the mechanism of synapse formation in the brain.

Keywords: glutamate receptor $\delta 2$, motor learning, neurexin, parallel fiber, Purkinje cell, synapse formation

\section{INTRODUCTION}

The cerebellum receives two excitatory afferents, the climbing fiber $(\mathrm{CF})$ and the mossy fiber-parallel fiber $(\mathrm{PF})$ pathway, both converging onto Purkinje cells (PCs) that are the sole neurons sending outputs from the cerebellar cortex. Glutamate receptors (GluRs) play central roles in synaptic transmission, synaptic plasticity, learning, memory, and development in the brain. Ionotropic GluRs have been classified into three major subtypes, the $\alpha$-amino-3-hydroxy-5-methyl-4-isozaxole propionic acid (AMPA), kainate and $N$-methyl-D-aspartate (NMDA) receptors, based on the pharmacological, and electrophysiological properties (Mayer and Westbrook, 1987; Monaghan et al., 1989). We found the $\delta$ subtype of GluR by molecular cloning (Yamazaki et al., 1992). With respect to the amino-acid sequence identity, the GluR $\delta$ (GluD) subtype is positioned between the NMDA and non-NMDA (AMPA/kainite) subtypes (Yamazaki et al., 1992; Araki et al., 1993; Lomeli et al., 1993; Hollmann and Heinemann, 1994; Mori and Mishina, 1995; Mishina, 2000). GluR 82 , the second member of this subfamily, is selectively expressed in cerebellar PCs (Araki et al., 1993; Lomeli et al., 1993). Interestingly, GluR 22 is localized at PF-PC synapses in cerebellar PCs, but not at CF-PC synapses (Takayama et al., 1996; Landsend et al., 1997). GluR $\delta 2$ knockout mice showed severe impairments of long-term depression (LTD) at the PF-PC synapse, motor learning, and motor coordination (Funabiki et al., 1995; Hirano et al., 1995; Kashiwabuchi et al., 1995; Kishimoto et al., 2001). Furthermore, a significant number of PC spines lack synaptic contacts with PF terminals and multiple CF innervation to PCs is sustained in GluR $\delta 2$ mutant mice (Kashiwabuchi et al., 1995; Kurihara et al., 1997; Hashimoto et al., 2001; Ichikawa et al., 2002). Thus, GluR 22 plays a central role in the synaptic plasticity, motor learning, and neural wiring of cerebellar PCs. Since there is no evidence for GluR $\delta 2$ channel activities, although lurcher mutation (Ala639Thr) transformed GluR $\delta 2$ to constitutively active channels (Zuo et al., 1997), it remained unknown how GluR $\delta 2$ regulates cerebellar wiring and function. Recent findings provided significant insights on the issue.

\section{GIUR 22 REGULATES SYNAPTIC PLASTICITY AND MOTOR LEARNING THROUGH THE C-TERMINAL DOMAIN}

Studies with conventional and conditional knockout mice revealed that GluR $\delta 2$ is essential for synapse formation, synaptic plasticity, motor learning, and the restriction of CF territory (Figure 1). However, the causal relationships of these phenotypes remained to be clarified. The C-terminal cytoplasmic region of GluR $\delta 2$ contains at least three domains for protein-protein interactions (Roche et al., 1999; Uemura et al., 2004; Yawata et al., 2006). The postsynaptic density (PSD)-95/Discs large/zona occludens 1 (PDZ)-binding domain at the C-terminal, designated as the T site (Uemura et al., 2007), interacts with PSD-93, PTPMEG, Delphilin, nPIST, and S-SCAM (Roche et al., 1999; Hironaka et al., 2000; Miyagi et al., 2002; Yue et al., 2002; Yap et al., 2003). 

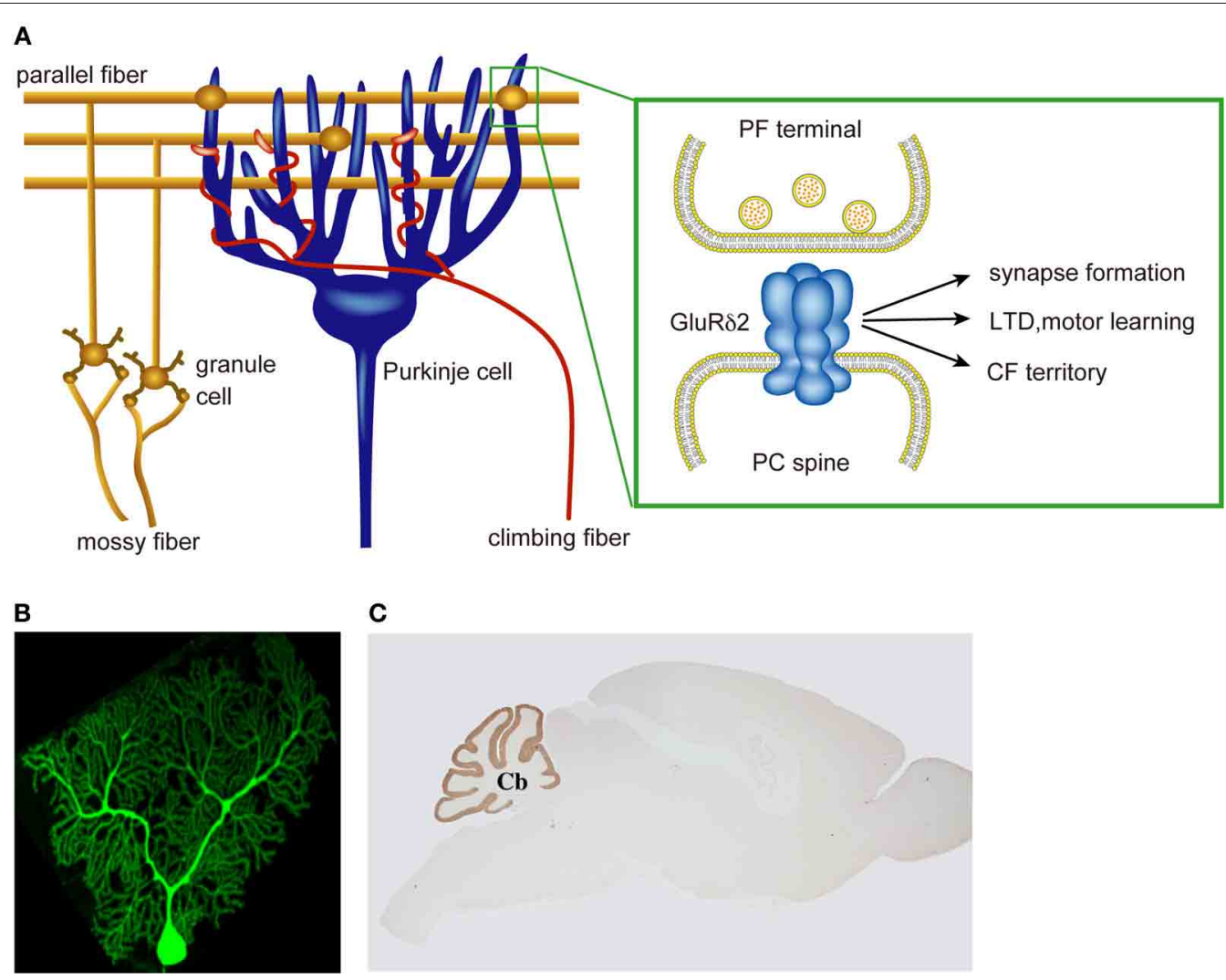

FIGURE 1 | Multiple roles of PC-specific GluR $\delta 2$ in cerebellar wiring and function. (A) A cerebellar PC receives a large numbers of PF innervation at distal dendrites and a single CF innervation at proximal dendrites. GluR $\delta 2$ is selectively expressed in cerebellar PCs and exclusively localized at the PF-PC synapse. GluR $\delta 2$ at the PF synapse regulates PF-PC synapse formation, LTD induction, motor learning, and CF territory. (B) A cerebellar PC visualizes by EGFP. (C) Immunohistochemical staining of a mouse brain with anti-GluR $\delta 2$ antibody.
In the middle of the C-terminal cytoplasmic region, there is the domain that interacts with Shank scaffold proteins, designated as the S segment (Uemura et al., 2004). The membrane-proximal domain of the C-terminal cytoplasmic region of GluR $\delta 2$ interacts with PICK1 (Yawata et al., 2006).

We generated GluR $\delta 2 \Delta \mathrm{T}$ mice carrying mutant GluR $\delta 2$ lacking the $\mathrm{T}$ site comprising seven amino acids at the C-terminal (Uemura et al., 2007). There were no significant differences in the amount of receptor proteins in the PSD fraction and in the density of GluR $\delta 2$ immunogold particles at PF-PC synapses between wild-type and GluR $\delta 2 \Delta \mathrm{T}$ mice. Thus, the C-terminal truncation exerted little effect on the synaptic localization of receptor proteins. Synaptic connections between PF terminals and PC spines were intact in GluR $\delta 2 \Delta \mathrm{T}$ mice. However, LTD induction at PF-PC synapses was impaired and the improvement of the performance in the accelerating rotarod test was diminished in the mutant mice. The importance of the GluR $\delta 2 \mathrm{C}$ terminal in cerebellar LTD and motor learning is consistent with the observations that in PTPMEG mutant mice, LTD at PF-PC synapses was significantly attenuated and rapid acquisition of the cerebellum-dependent delay eyeblink conditioning was impaired (Kina et al., 2007). These results suggest that the C-terminal T site of GluR $\delta 2$ is essential for LTD induction and motor learning, but is dispensable for PF-PC synapse formation (Uemura et al., 2007).
Delphilin is selectively expressed in cerebellar PCs except for a slight expression in the thalamus and is exclusively localized at the postsynaptic junction site of the PF-PC synapse (Miyagi et al., 2002). The characteristic expression pattern of Delphilin is reminiscent of GluR $\delta 2$. Delphilin knockout mice showed no detectable abnormalities in cerebellar histology, PC cytology, and PC synapse formation (Takeuchi et al., 2008). Delphilin ablation exerted little effect on the synaptic localization of GluR $\delta 2$. However, LTD induction was facilitated at PF-PC synapses and intracellular $\mathrm{Ca}^{2+}$ required for the induction of LTD appeared to be reduced in Delphilin knockout mice. We further showed that the gain-increase adaptation of the optokinetic response (OKR) was enhanced in the mutant mice. These findings suggest that synaptic plasticity at PF-PC synapses is a crucial rate-limiting step in OKR gain-increase adaptation, a simple form of motor learning (Takeuchi et al., 2008).

\section{GluR82 TRIGGERS PF-PC SYNAPSE FORMATION BY TRANS-SYNAPTIC INTERACTION WITH NEUREXINS THROUGH CbIn1}

We examined the role of GluR $\delta 2$ in the adult brain using inducible and cerebellar PC-specific gene targeting on the C57BL/6 genetic background (Takeuchi et al., 2005). When GluR $\delta 2$ proteins were 
diminished, a significant number of PC spines lost their synaptic contacts with PF terminals. Thus, studies with conventional and inducible knockout mice indicate that the formation and maintenance of PF-PC synapses are critically dependent on GluR82 in vivo (Kashiwabuchi et al., 1995; Takeuchi et al., 2005). Concomitant with the decrease of postsynaptic GluR $\delta 2$ proteins, presynaptic active zones shrank progressively and PSD expanded, resulting in mismatching between pre- and postsynaptic specializations at PF-PC synapse (Figure 2). Furthermore, GluR $\delta 2$ and PSD-93 proteins were concentrated at the contacted portion of mismatched synapses, while AMPA receptors distributed in both the contacted and dissociated portions. Thus, postsynaptic GluR $\delta 2$ is a key regulator of the presynaptic active zone and PSD organization at PF-PC synapses. Based on the direct relationship between the density of postsynaptic GluR $\delta 2$ and the size of presynaptic active zones in GluR $\delta 2$ mutant mice generated by inducible Cre-mediated ablation, we proposed that GluR $\delta 2$ makes a physical linkage between the active zone and PSD by direct or indirect interaction with an active zone component (Takeuchi et al., 2005). Indirect interaction through PSD proteins appears to be less likely since the C-terminal truncation of GluR $\delta 2$ has little effect on
PF-PC synapse formation, while the mutation impairs cerebellar LTD and motor learning (Uemura et al., 2007).

To identify the key domain responsible for synapse formation, we expressed GluR $\delta 2$ in HEK293T cells and cultured the transfected cells with cerebellar granule cells (GCs) (Uemura and Mishina, 2008) (Figure 3). Numerous punctate signals for presynaptic markers were observed on the surface of HEK293T cells expressing GluR $\delta 2$. The presynaptic specializations of cultured GCs induced by GluR $\delta 2$ were capable of exo- and endocytosis as indicated by FM1-43 dye labeling. Replacement of the extracellular N-terminal domain (NTD) of GluR $\delta 2$ with that of the AMPA receptor GluR $\alpha 1$ abolished the inducing activity. The NTD of GluR $\delta 2$ (GluR $\delta 2-N T D)$ coated on beads successfully induced the accumulation of presynaptic specializations. These results suggest that GluR $\delta 2$ triggers synapse formation by direct interaction with presynaptic component(s) through the NTD (Uemura and Mishina, 2008; Kakegawa et al., 2009; Kuroyanagi et al., 2009; Mandolesi et al., 2009).

To seek for GluR $\delta 2$ interacting proteins, the presynaptic differentiation of cerebellar GCs was induced by treatment with GluR82-NTD-coated magnetic beads and then
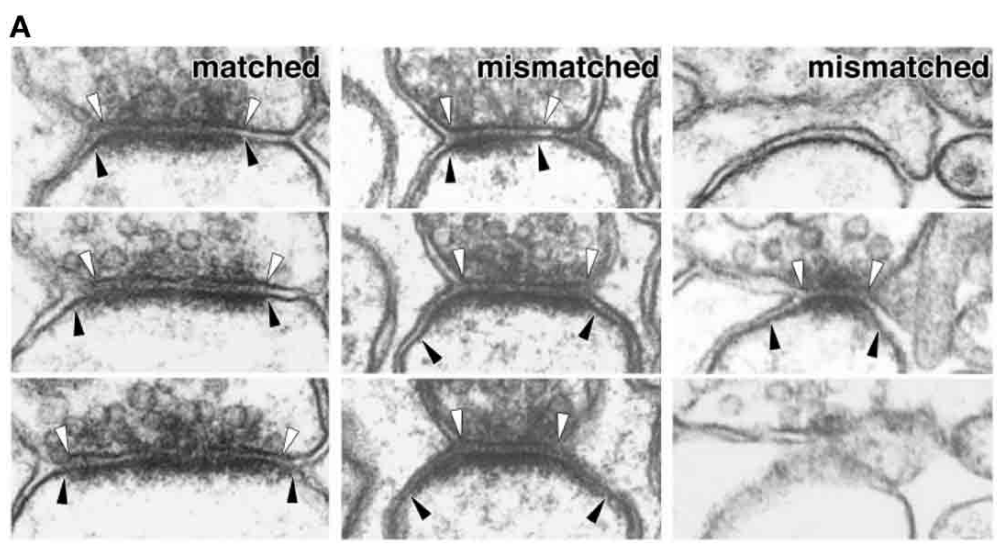

B
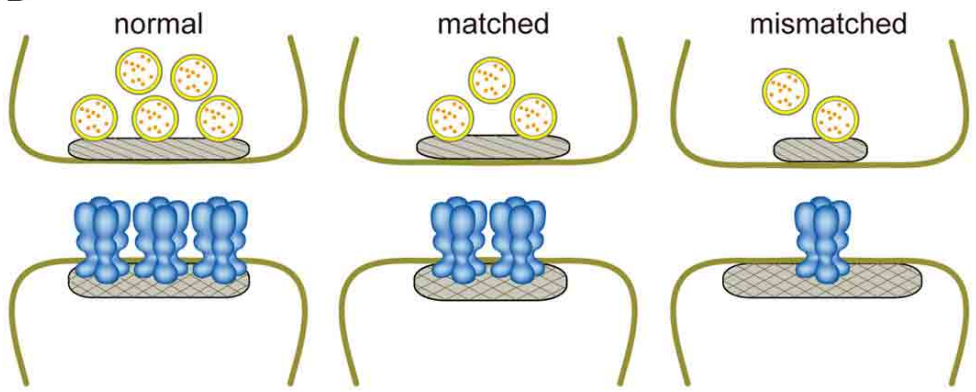

free

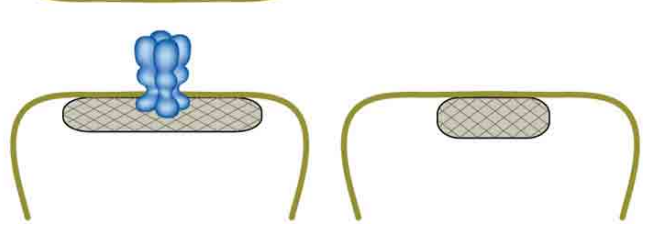

FIGURE 2 | Close relationship between the amount of GluR $\delta 2$ protein and the size of the active zone. (A) Ablation of GluR 22 , when induced in the adult brain, resulted in the disruption of synaptic connections with PF terminals in a significant number of PC spines. In addition, some of residual PF-PC synapses show mismatching between pre- and postsynaptic specializations (Takeuchi et al., 2005). White and black arrowheads indicate the edges of active zone and PSD, respectively. (B) Schematic presentation of the relationships between the amount of GluR $\delta 2$ protein and the sizes of presynaptic active zone (hatched) and PSD (cross-hatched). The length of active zone became

shorter in the order of normal, matched, and mismatched synapses according to the decrease of the density of GluR $\delta 2$-immunogold labeling at postsynaptic sites (Takeuchi et al., 2005). Based on the direct relationship between the density of postsynaptic GluR $\delta 2$ and the size of presynaptic active zones in GluR $\delta 2$ mutant mice, we proposed that GluR $\delta 2$ makes a physical linkage between the active zone and PSD by interaction with an active zone component. Normal, normal synapse of wild-type mice; matched, matched synapse of induced GluR $\delta 2 \mathrm{KO}$ mice; mismatched, mismatched synapse of induced GluR $\delta 2$ KO mice; free, free spine of induced GluR $\delta 2$ KO mice. 

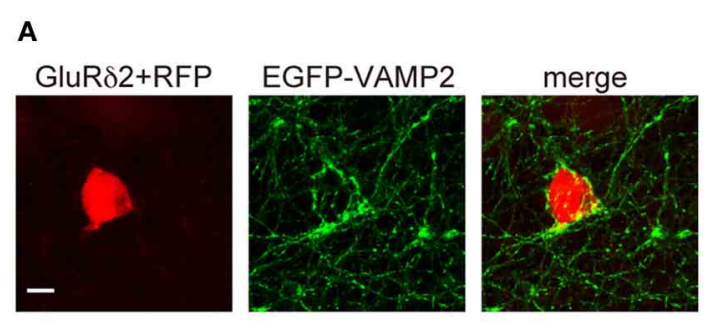

B

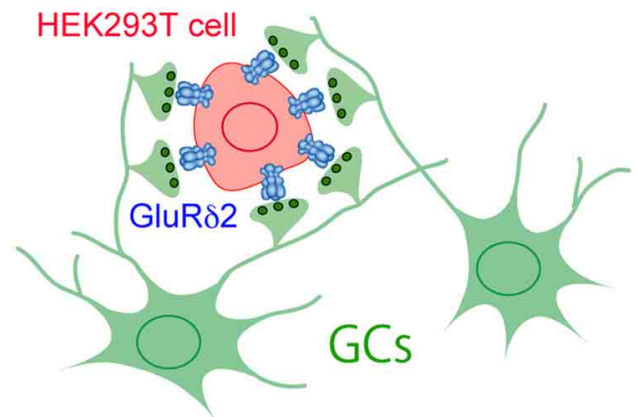

FIGURE 3 | Induction of presynaptic differentiation by GluR $\delta 2$.

(A) HEK293T cells transfected with expression vectors for GluR $\delta 2$ and tagRFP (red) were seeded on top of cultured cerebellar neurons transfected with an expression vector for vesicle-associated membrane protein-2 (VAMP-2) fused with EGFP at its $N$ terminus (EGFP-VAMP2) (green). After 2 days of co-culture, cells were immunostained for EGFP. Note that numerous EGFP-VAMP2 signals accumulated on the surface of HEK293T cells expressing GluR $\delta 2$. Scale bar represents $10 \mu \mathrm{m}$. (B) Schematic presentation of the accumulation of GC axon terminals on the surface of HEK293T cells expressing GluR $\delta 2$.

surface proteins of cerebellar GC axons were covalently bound to GluR82-NTD using non-permeable cross-linker 3,3'dithiobis(sulfosuccinimidylpropionate). Comparative analysis of the isolated proteins by liquid chromatography-tandem mass spectrometry identified neurexin (NRXN) 1, NRXN2, FAT2, protein tyrosine phosphatase $\sigma(\mathrm{PTP} \sigma)$, and cerebellin 1 precursor protein (Cbln1) as possible GluR $\delta 2$-interacting proteins (Uemura et al., 2010). NRXN1, NRXN2, FAT2, and PTP $\sigma$ are membrane proteins (Pulido et al., 1995; Nakayama et al., 2002; Südhof, 2008), while Cbln1 is a glycoprotein secreted from cerebellar GCs (Bao et al., 2005). After a series of selections, we found robust binding signals of GluR $\delta 2-N T D$ on the surface of HEK293T cells transfected with NRXN1 $\beta$ or NRXN2 $\beta$ in the presence of Cbln1. It is known that presynaptic NRXNs bind to postsynaptic neuroligins (NLGNs) forming trans-synaptic cell adhesion complexes (Ichtchenko et al., 1995; Scheiffele et al., 2000; Graf et al., 2004) and NLGNs preferentially bind to NRXN variants lacking splice segment 4 (S4) (Boucard et al., 2005; Chih et al., 2005; Comoletti et al., 2006). In contrast to NLGNs, GluR $\delta 2$ selectively interacts with NRXN variants containing S4. NRXN variants containing S4 were expressed in the cerebellum but those lacking S4 were hardly detectable except for early stages of development, while both variants were found in the cerebral cortex and hippocampus (Uemura et al., 2010; Iijima et al., 2011).
Direct binding experiments showed that GluR $\delta 2$ is a receptor for Cbln1 and NRXN is another receptor for Cbln1 (Uemura et al., 2010). The $K_{D}$ value of Cbln1 for the NTD of GluR $\delta 2$ estimated by surface plasmon resonance binding assays is $16.5 \mathrm{nM}$ and that for the extracellular domain (ECD) of NRXN1 $\beta$ is $0.17 \mathrm{nM}$. These values suggest high affinity interactions of GluR $\delta 2$, Cbln1 and NRXN as compared with $\mathrm{K}_{\mathrm{D}}$ values $(\sim 200$ to $\sim 600 \mathrm{nM}$ ) reported for the interactions between NLGNs and NRXNs (Comoletti et al., 2003; Koehnke et al., 2008). Matsuda et al. (2010) also reported the interaction between Cbln1 and GluR $\delta 2$. Since Cbln1 is a ligand for both GluR $\delta 2$ and NRXN, we propose a model in which postsynaptic GluR $\delta 2$ interacts with presynaptic NRXN through Cbln1 and this ternary interaction provides a physical linkage between PSD and active zone (Uemura et al., 2010). The synaptogenic activity of GluR $\delta 2$ is hindered by knockout of Cbln1 and by small interference RNA-mediated knockdown of NRXNs. Furthermore, the synaptogenic activity of Cbln 1 in cerebellar primary cultures and in vivo was abolished by the NTD of GluR $\delta 2$ and the ECD of NRXN1 $\beta$ (Figure 4). These results suggest that the trans-synaptic interaction of postsynaptic GluR $\delta 2$ and presynaptic NRXNs through Cbln1 mediates PF-PC synapse formation in the cerebellum (Uemura et al., 2010). This model well explains previous observations that the size of the presynaptic active zone shrank progressively concomitant with the decrease of postsynaptic GluR $\delta 2$ proteins upon inducible Cremediated GluR $\delta 2$ ablation (Takeuchi et al., 2005) and that Cbln1 knockout mice phenotypically mimic GluR $\delta 2$ knockout mice (Hirai et al., 2005).

\section{ASSEMBLY STOICHIOMETRY OF THE TRANS-SYNAPTIC TRIAD}

Cumulative evidence indicates the tetrameric assembly of the AMPA/kainate- and NMDA-type GluRs (Laube et al., 1998; Rosenmund et al., 1998; Bowie and Lange, 2002; Sun et al., 2002; Weston et al., 2006). The mobility of GluR $\delta 2$ molecules from the membrane fraction corresponded to the size of the tetramer in blue native PAGE. GluR $\delta 2$ band collapsed into monomeric and dimeric intermediates by the treatment of $1 \%$ SDS. These behaviors were similar between GluR $\delta 2$ and AMPA-type GluR. These results suggest that GluR $\delta 2$ exists as a tetramer in the membrane. On the other hand, GluR $82-\mathrm{NTD}$ assembled into a stable homodimer. The NTD of ionotropic GluRs with tetrameric structure assembles as a dimer of dimers (Schorge and Colquhoun, 2003; Tichelaar et al., 2004; Midgett and Madden, 2008; Kumar et al., 2009) and tetrameric iGluRs have 2-fold symmetry rather than 4-fold symmetry (Armstrong and Gouaux, 2000; Sobolevsky et al., 2004, 2009; Nanao et al., 2005).

When incubated with cultured cerebellar GCs, dimeric GluR 2 2-NTD exerted little effect on the intensities of punctate immunostaining signals for Bassoon and vesicular glutamate transporter 1 (VGluT1). In contrast, tetrameric GluR 82 NTD prepared by cross-linking dimeric GluR $\delta 2-N T D-F c$ using $\mathrm{F}\left(\mathrm{ab}^{\prime}\right)_{2}$ of anti-Fc antibody enhanced the accumulation of the active zone and synaptic vesicle proteins in axons of cultured GCs. These results suggest that native GluR $\delta 2$ is 


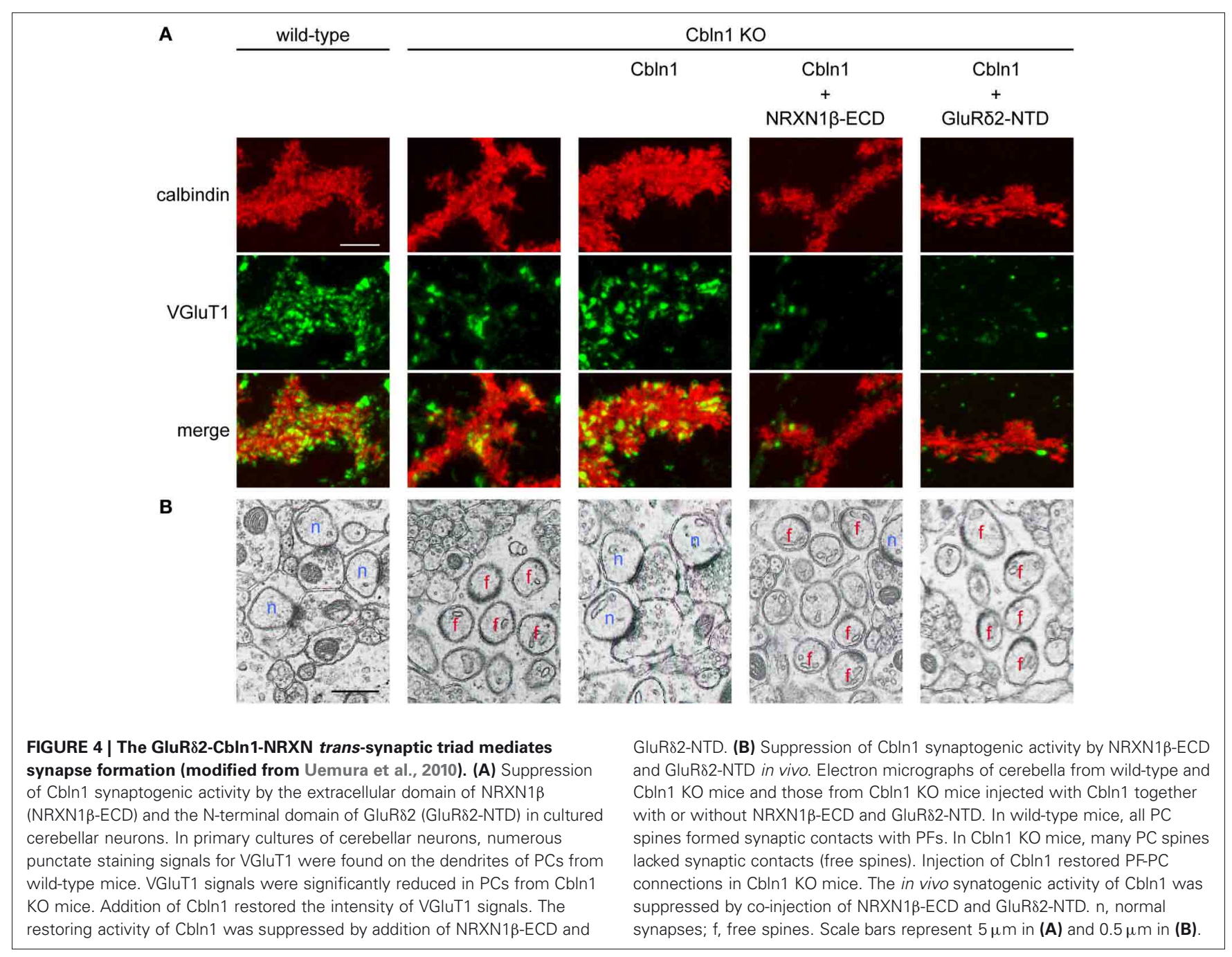

assembled into a tetramer and this tetrameric assembly is essential for GluR $\delta 2$ to induce presynaptic differentiation (Lee et al., 2012).

Affinities of a series of Cbln1 mutants for GluR $\delta 2-N T D$ and NRXN1 $\beta$-ECD suggest that the binding sites of Cbln1 for GluR $\delta 2$ and NRXN1 $\beta$ are differential rather than identical. In addition, no competition was detectable in the binding to Cbln1 between GluR $\delta 2-N T D$ and the laminin-neurexin-sex hormonebinding globulin (LNS) domain of NRXN1 $\beta$ during triad formation. These results suggest that GluR $\delta 2$ and Cbln 1 interact with each other rather independently of Cbln1-NRXN1 $\beta$ interaction and vice versa. We thus examined the assembly stoichiometries of GluR 2 2-Cbln1 and Cbln1-NRXN1 $\beta$ complexes one by one. Both fast protein liquid chromatography gel-filtration assay and isothermal titration calorimetry analysis consistently showed that dimeric GluR82-NTD and hexameric Cbln1 assembled in the molar ratio of one to one, while hexameric Cbln 1 and monomeric NRXN1 $\beta$-LNS assembled in the molar ratio of one to two. Since native GluR $\delta 2$ exists as a tetramer in the membrane and the tetramerization is essential for GluR $82-N T D$ to stimulate the accumulation of Bassoon and VGluT1 in the axons of cultured GCs, we suggest that the synaptogenic triad is composed of one molecule of tetrameric GluR $\delta 2$, two molecules of hexameric Cbln1 and four molecules of monomeric NRXN (Lee et al., 2012).

\section{MECHANISM OF GIURס2-MEDIATED SYNAPSE FORMATION}

During development, axons of immature neurons show a capacity for evoked recycling of synaptic vesicles and clusters of the vesicles along axonal segments, even in the absence of target cells (Ziv and Garner, 2004; Jin and Garner, 2008). However, the synaptic vesicle aggregation, in the absence of a postsynaptic contact, is not stably anchored to a given region of the cell surface. Contacts with postsynaptic sites trigger the stabilization and maturation of synapses. In cultured cerebellar GCs, the majority of varicosities containing presynaptic proteins are not apposed to definite postsynaptic structures (Marxen et al., 1999; Urakubo et al., 2003). Cbln1 is a high-affinity ligand for NRXNs (Uemura et al., 2010; Joo et al., 2011) and is secreted from cerebellar GCs (Bao et al., 2005), suggesting that the interaction between secreted Cbln1 and presynaptic NRXNs takes place before PF-PC synapse formation. However, punctate staining signals for Bassoon were comparable between GC cultures from wild-type and Cbln1 knockout mice. The addition of Cbln 1 to GC cultures exerted little effect on the intensity of Bassoon 
signals. Thus, the formation of NRXN dimers is not sufficient to induce presynaptic differentiation. Consistently, GluR $\delta 2-N T D$ dimer that binds to one molecule of Cbln1 failed to induce presynaptic differentiation. In contrast, GluR $\delta 2-N T D$ tetramer stimulated the accumulation of punctate signals for active zone protein Bassoon and synaptic vesicle protein VGluT1 in cultured cerebellar GCs. Since GluR $\delta 2-N T D$ tetramer is soluble, it is unlikely that this stimulating effect is due to anchoring presynaptic proteins. Our results suggest that tetrameric GluR $\delta 2-$ NTD assembles two molecules of Cbln1 and four molecules of NRXNs, whereas dimeric GluR $82-N T D$ interacts with one molecule of Cbln1 and two molecules of NRXNs. Thus, clustering of four NRXNs by tetrameric GluR $82-\mathrm{NTD}$ via two Cbln1 is a key step to trigger presynaptic differentiation (Lee et al., 2012). Taken together, our results suggest the mechanism of PFPC synapse formation as follows. Cbln 1 secreted from cerebellar GCs may interact with presynaptic NRXNs before PF-PC synapse formation. However, Cbln1-induced NRXN dimerization is not sufficient to trigger presynaptic differentiation. When the contact between the PF terminal and PC spine takes place, GluR $\delta 2$ triggers synapse formation by clustering four NRXNs through triad formation (Figure 5). Since NRXNs interact with synaptotagmin, CASK, Mint and syntenin through its C-terminal (Hata et al., 1993, 1996; Butz et al., 1998; Biederer and Südhof, 2000; Grootjans et al., 2000) and the C-terminal of NRXN is critical for the induction of presynaptic differentiation in vitro (Dean et al., 2003), tetramerization of NRXNs may stimulate the clustering of these scaffold proteins leading to the organization of transmitter release machineries (Butz et al., 1998; Maximov et al., 1999; Biederer and Südhof, 2000, 2001).

\section{CONCLUSION}

Cerebellar PC-specific GluR $\delta 2$ plays essential roles in synapse formation, synaptic plasticity and motor learning. The NTD of GluR $\delta 2$ is responsible for synapse formation, whereas the C-terminal domain is essential for LTD induction and motor learning. Thus, GluR $\delta 2$ is the molecule that bridges synapse formation and motor learning in the cerebellum.

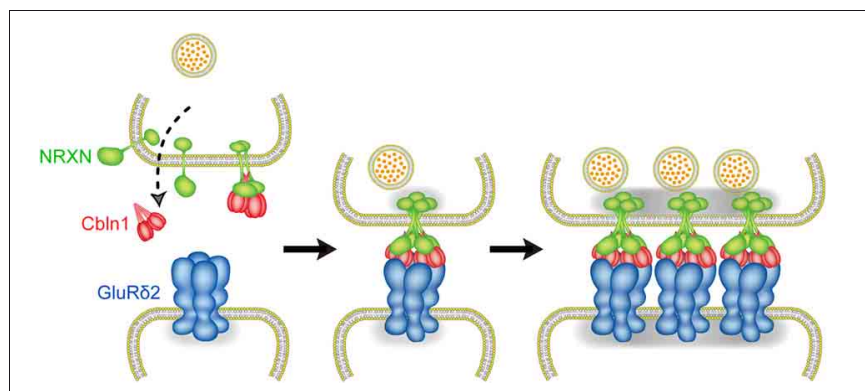

FIGURE 5 | Molecular mechanism of PF-PC synapse formation. Before PF-PC synapse formation, Cbln1 secreted from cerebellar GCs may interact with presynaptic NRXNs. Cbln1-induced NRXN dimerization is not sufficient to trigger presynaptic differentiation. When the contact between the PF terminal and PC spine takes place, GluR $\delta 2$ triggers synapse formation by clustering four NRXNs through triad formation.
Synapse formation is the key step in the development of neuronal networks. Precise synaptic connections between nerve cells in the brain provide the basis of perception, learning, memory, and cognition. Although a number of trans-synaptic cell adhesion molecules have been identified that play roles in preand postsynaptic differentiation of cultured hippocampal neurons, the precise roles of these molecules in synapse formation in vivo remain elusive (Scheiffele et al., 2000; Dean et al., 2003; Graf et al., 2004; Waites et al., 2005; Varoqueaux et al., 2006; Dalva et al., 2007; McAllister, 2007; Südhof, 2008; Shen and Scheiffele, 2010; Williams et al., 2010; Siddiqui and Craig, 2011). Our results provide evidence that the trans-synaptic interaction of postsynaptic GluR $\delta 2$ and presynaptic NRXNs through Cbln 1 mediates PF-PC synapse formation in vivo in the cerebellum (Uemura et al., 2010). Furthermore, the stoichiometry of synaptogenic GluR $\delta 2-C b \ln 1-\mathrm{NRXN}$ triad suggests that GluR $\delta 2$ triggers presynsptic differentiation by clustering four NRXNs (Lee et al., 2012). It will be essential for the elucidation of synaptogenesis mechanism to investigate how NRXN clustering initiates the formation of presynaptic active zone. Interestingly, approximately half of PF-PC synapses survived in GluR $\delta 2$ knockout mice (Kashiwabuchi et al., 1995; Kurihara et al., 1997). There may be at least two types of PF-PC synapses, GluR $\delta 2$ dependent and independent synapses. Alternatively, other synaptogenic molecule(s) may partly compensate GluR $\delta 2$ deficiency in the knockout mice. It should be noted that the organization and composition of remaining PF-PC synapses in the absence of GluR $\delta 2$ appear to be altered, suggesting that GluR $\delta 2$ also plays a role as a PSD organizer (Takeuchi et al., 2005; Yamasaki et al., 2011). Further investigation of the structure and function of the GluR $\delta 2-C b \ln 1-\mathrm{NRXN}$ synaptogenic triad will provide a clue to understand how central synapses are formed, mature, show plastic changes, and mediate learning and memory.

During development, PC circuitry is established through heterosynaptic competition between PFs and CFs (Mariani et al., 1977; Crépel, 1982). GluR 22 regulates the PC wiring by suppressing invasion of CF branches to the territory of PF innervation and to neighboring PCs (Kashiwabuchi et al., 1995; Hashimoto et al., 2001; Ichikawa et al., 2002; Uemura et al., 2007; Miyazaki et al., 2010). Weakened PF inputs due to the decrease of PF-PC synapses in GluR $\delta 2$ mutant mice may result in CF invasion to the PF territory (Hashimoto et al., 2001; Ichikawa et al., 2002). However, the territory of CF innervation expanded distally to spiny branchlets in GluR $\delta 2 \Delta \mathrm{T}$ mice with intact PF-PC synaptic connections (Uemura et al., 2007). GluR $\delta 2$ is localized at PF-PC synapses but not at CF synapses (Takayama et al., 1996; Landsend et al., 1997). Thus, GluR $\delta 2$ should suppress the distal extension and ectopic innervation of CF axon terminals by the signaling through the C-terminal $\mathrm{T}$ site (Uemura et al., 2007).

\section{ACKNOWLEDGMENTS}

This work was supported in part by research grants from the Ministry of Education, Culture, Sports, Science, and Technology of Japan. 


\section{REFERENCES}

Araki, K., Meguro, H., Kushiya, E., Takayama, C., Inoue, Y., and Mishina, M. (1993). Selective expression of the glutamate receptor channel $\delta 2$ subunit in cerebellar Purkinje cells. Biochem. Biophys. Res. Commun. 197, 1267-1276.

Armstrong, N., and Gouaux, E. (2000). Mechanisms for activation and antagonism of an AMPA-sensitive glutamate receptor: crystal structure of the GluR2 ligand binding core. Neuron 28, 165-181.

Bao, D., Pang, Z., and Morgan, J. I. (2005). The structure and proteolytic processing of Cbln1 complexes. J. Neurochem. 95, 618-629.

Biederer, T., and Südhof, T. C. (2000). Mints as adaptors: direct binding to neurexins and recruitment of Munc18. J. Biol. Chem. 275, 39803-39806.

Biederer, T., and Südhof, T. C. (2001). CASK and Protein 4.1 support Factin nucleation on neurexins. J. Biol. Chem. 276, 47869-47876.

Boucard, A. A., Chubykin, A. A., Comoletti, D., Taylor, P., and Südhof, T. C. (2005). A splice code for trans-synaptic cell adhesion mediated by binding of neuroligin 1 to $\alpha$ - and $\beta$-neurexins. Neuron 48 , 229-236.

Bowie, D., and Lange, G. D. (2002). Functional stoichiometry of glutamate receptor desensitization. J. Neurosci. 22, 3392-3403.

Butz, S., Okamoto, M., and Südhof, T. C. (1998). A tripartite protein complex with the potential to couple synaptic vesicle exocytosis to cell adhesion in brain. Cell 94, 773-782.

Chih, B., Engelman, H., and Scheiffele, P. (2005). Control of excitatory and inhibitory synapse formation by neuroligins. Science 307, 1324-1328.

Comoletti, D., Flynn, R., Jennings, L. L., Chubykin, A., Matsumura, T., Hasegawa, H., et al. (2003). Characterization of the interaction of a recombinant soluble neuroligin-1 with neurexin-1 $\beta$. J. Biol. Chem. 278, 50497-50505.

Comoletti, D., Flynn, R. E., Boucard, A. A., Demeler, B., Schirf, V., Shi, J., et al. (2006). Gene selection, alternative splicing, and post-translational processing regulate neuroligin selectivity for $\beta$-neurexins. Biochemistry 45, 12816-12827.

Crépel, F. (1982). Regression of functional synapses in the immature mammalian cerebellum. Trends Neurosci. 5, 266-269.

Dalva, M. B., McClelland, A. C., and Kayser, M. S. (2007). Cell adhesion molecules: signalling functions at the synapse. Nat. Rev. Neurosci. 8, 206-220.

Dean, C., Scholl, F. G., Choih, J., DeMaria, S., Berger, J., Isacoff, E., et al. (2003). Neurexin mediates the assembly of presynaptic terminals. Nat. Neurosci. 6, 708-716.

Funabiki, K., Mishina, M., and Hirano, T. (1995). Retarded vestibular compensation in mutant mice deficient in $\delta 2$ glutamate receptor subunit. Neuroreport 7, 189-192.

Graf, E. R., Zhang, X., Jin, S. X., Linhoff, M. W., and Craig, A. M. (2004). Neurexins induce differentiation of GABA and glutamate postsynaptic specializations via neuroligins. Cell 119, 1013-1026.

Grootjans, J. J., Reekmans, G., Ceulemans, H., and David, G. (2000). Syntenin-Syndecan binding requires Syndecan-Synteny and the co-operation of both PDZ domains of Syntenin. J. Biol. Chem. 275, 19933-19941.

Hashimoto, K., Ichikawa, R., Takechi, H., Inoue, Y., Aiba, A., Sakimura, K., et al. (2001). Roles of glutamate receptor $\delta 2$ subunit (GluR $\delta 2)$ and metabotropic glutamate receptor subtype 1 (mGluR1) in climbing fiber synapse elimination during postnatal cerebellar development. J. Neurosci. 21, 9701-9712.

Hata, Y., Butz, S., and Südhof, T. C. (1996). CASK: a novel dlg/PSD95 homolog with an N-terminal calmodulin-dependent protein kinase domain identified by interaction with neurexins. J. Neurosci. 16, 2488-2494.

Hata, Y., Davletov, B., Petrenko, A. G., Jahn, R., and Südhof, T. C. (1993). Interaction of synaptotagmin with the cytoplasmic domains of neurexins. Neuron 10, 307-315.

Hirai, H., Pang, Z., Bao, D., Miyazaki, T., Li, L., Miura, E., et al. (2005). Cbln1 is essential for synaptic integrity and plasticity in the cerebellum. Nat. Neurosci. 8, 1534-1541.

Hirano, T., Kasono, K., Araki, K., and Mishina, M. (1995). Suppression of LTD in cultured Purkinje cells deficient in the glutamate receptor $\delta 2$ subunit. Neuroreport 6, 524-526.
Hironaka, K., Umemori, H., Tezuka, T., Mishina, M., and Yamamoto, T. (2000). The protein-tyrosine phosphatase PTPMEG interacts with glutamate receptor $\delta 2$ and $\varepsilon$ subunits. J. Biol. Chem. 275, 16167-16173.

Hollmann, M., and Heinemann, S. (1994). Cloned glutamate receptors. Annu. Rev. Neurosci. 17, 31-108.

Ichikawa, R., Miyazaki, T., Kano, M., Hashikawa, T., Tatsumi, H., Sakimura, K., et al. (2002). Distal extension of climbing fiber territory and multiple innervation caused by aberrant wiring to adjacent spiny branchlets in cerebellar Purkinje cells lacking glutamate receptor GluR $\delta 2$. J. Neurosci. 22, 8487-8503.

Ichtchenko, K., Hata, Y., Nguyen, T., Ullrich, B., Missler, M., Moomaw, C., et al. (1995). Neuroligin 1: a splice site-specific ligand for $\beta$-neurexins. Cell 81, 435-443.

Iijima, T., Wu, K., Witte, H., HannoIijima, Y., Glatter, T., Richard, S., et al. (2011). SAM68 regulates neuronal activity-dependent alternative splicing of neurexin-1. Cell 147, 1601-1614.

Jin, Y., and Garner, C. C. (2008). Molecular mechanisms of presynaptic differentiation. Annu. Rev. Cell Dev. Biol. 24, 237-262.

Joo, J.-Y., Lee, S.-J., Uemura, T., Yoshida, T., Yasumura, M., Watanabe, M., et al. (2011). Differential interactions of cerebellin precursor protein (Cbln) subtypes and neurexin variants for synapse formation of cortical neurons. Biochem. Biophys. Res. Commun. 406, 627-632.

Kakegawa, K., Miyazaki, T., Kohda, K., Matsuda, K., Emi, K., Motohashi, J., et al. (2009). The N-terminal domain of GluD2 (GluR 22 ) recruits presynaptic terminals and regulates synaptogenesis in the cerebellum in vivo. J. Neurosci. 29, 5738-5748.

Kashiwabuchi, N., Ikeda, K., Araki, K., Hirano, T., Shibuki, K., Takayama, C., et al. (1995). Impairment of motor coordination, Purkinje cell synapse formation, and cerebellar long-term depression in GluR 82 mutant mice. Cell 81, 245-252.

Kina, S., Tezuka, T., Kusakawa, S., Kishimoto, Y., Kakizawa, S. Hashimoto, K., et al. (2007) Involvement of protein-tyrosine phosphatase PTPMEG in motor learning and cerebellar long-term depression. Eur. J. Neurosci. 26, 2269-2278.
Kishimoto, Y., Kawahara, S., Suzuki, M., Mori, H., Mishina, M., and Kirino, Y. (2001). Classical eyeblink conditioning in glutamate receptor subunit $\delta 2$ mutant mice is impaired in the delay paradigm but not in the trace paradigm. Eur. J. Neurosci. 13, 1249-1253.

Koehnke, J., Jin, X., Trbovic, N., Katsamba, P. S., Brasch, J., Ahlsen, G., et al. (2008). Crystal structures of $\beta$-neurexin 1 and $\beta$-neurexin 2 ectodomains and dynamics of splice insertion sequence 4. Structure 16, 410-421.

Kumar, J., Schuck, P., Jin, R., and Mayer, M. L. (2009). The N-terminal domain of GluR6-subtype glutamate receptor ion channels. Nat. Struct. Mol. Biol. 16, 631-638.

Kurihara, H., Hashimoto, K., Kano, M., Takayama, C., Sakimura, K., Mishina, M., et al. (1997). Impaired parallel fiber-Purkinje cell synapse stabilization during cerebellar development of mutant mice lacking the glutamate receptor $\delta 2$ subunit. J. Neurosci. 17, 9613-9623.

Kuroyanagi, T., Yokoyama, M., and Hirano, T. (2009). Postsynaptic glutamate receptor $\delta$ family contributes to presynaptic terminal differentiation and establishment of synaptic transmission. Proc. Natl. Acad. Sci. U.S.A. 196, 4912-4916.

Landsend, A. S., Amiry-Moghaddam, M., Matsubara, A., Bergersen, L., Usami, S., Wenthold, R. J., et al. (1997). Differential localization of $\delta$ glutamate receptors in the rat cerebellum: coexpression with AMPA receptors in parallel fiber-spine synapses and absence from climbing fiber-spine synapses. J. Neurosci. 17, 834-842.

Laube, B., Kuhse, J., and Betz, H. (1998). Evidence for a tetrameric structure of recombinant NMDA receptors. J. Neurosci. 18, 2954-2961.

Lee, S.-J., Uemura, T., Yoshida, T., and Mishina, M. (2012). GluR $\delta 2$ assembles four neurexins into trans-synaptic triad to trigger synapse formation. J. Neurosci. 32, 4688-4701.

Lomeli, H., Sprengel, R., Laurie, D. J., Köhr, G., Herb, A., Seeburg, P. H., et al. (1993). The rat delta-1 and delta-2 subunits extend the excitatory amino acid receptor family. FEBS Lett. 315, 318-322.

Mandolesi, G., Autuori, E., Cesa, R., Premoselli, F., Cesare, P., and Strata, P. (2009). GluR $\delta 2$ expression in the mature cerebellum of hotfoot mice 
promotes parallel fiber synaptogenesis and axonal competition. PLoS ONE 4:e5243. doi: 10.1371/journal. pone. 0005243

Mariani, J., Crepel., F., Mikoshiba, K., Changeux, J. P., and Sotelo, C. (1977). Anatomical, physiological and biochemical studies of the cerebellum from Reeler mutant mouse. Philos. Trans. R. Soc. Lond. B Biol. Sci. 281, 1-28.

Marxen, M., Volknandt, W., and Zimmermann, H. (1999). Endocytic vacuoles formed following a short pulse of $\mathrm{K}^{+}$-stimulation contain a plethora of presynaptic membrane proteins. Neuroscience 94 , 985-996.

Matsuda, K., Miura, E., Miyazaki, T., Kakegawa, W., Emi, K., Narumi, S., et al. (2010). Cbln1 is a ligand for an orphan glutamate receptor $\delta 2$, a bidirectional synapse organizer. Science 328, 363-368.

Maximov, A., Südhof, T. C., and Bezprozvannv, I. (1999). Association of neuronal calcium channels with modular adaptor proteins. J. Biol. Chem. 274, 24453-24456.

Mayer, M. L., and Westbrook, G. L. (1987). The physiology of excitatory amino acids in the vertebrate central nervous system. Prog. Neurobiol. 28, 197-276.

McAllister, A. K. (2007). Dynamic aspects of CNS synapse formation. Annu. Rev. Neurosci. 30, 425-450.

Midgett, C. R., and Madden, D. R. (2008). The quaternary structure of a calcium-permeable AMPA receptor: conservation of shape and symmetry across functionally distinct subunit assemblies. J. Mol. Biol. 382, 578-584.

Mishina, M. (2000). "Molecular diversity, structure, and function of glutamate receptor channels," in Handbook of Experimental Pharmacology 147, eds M. Endo, Y. Kurachi, and M. Mishina (Berlin: Springer Verlarg), 393-414.

Miyagi, Y., Yamashita, T., Fukaya, M., Sonoda, T., Okuno, T., Yamada, K., et al. (2002). Delphilin: a novel PDZ and formin homology domaincontaining protein that synaptically colocalizes and interacts with glutamate receptor $\delta 2$ subunit. J. Neurosci. 22, 803-814.

Miyazaki, T., Yamasaki, M., Takeuchi, T., Sakimura, K., Mishina, M., and Watanabe, M. (2010). Ablation of glutamate receptor GluR $\delta 2$ in adult Purkinje cells causes multiple innervation of climbing fibers by inducing aberrant invasion to parallel fiber innervation territory. J. Neurosci. 30, 15196-15209.

Monaghan, D. T., Bridges, R. J., and Cotman, C. W. (1989). The excitatory amino acid receptors: their classes, pharmacology, and distinct properties in the function of the central nervous system. Annu. Rev. Pharmacol. Toxicol. 29, 365-402.

Mori, H., and Mishina, M. (1995). Structure and function of the NMDA receptor channel. Neuropharmacology 34, 1219-1237.

Nakayama, M., Nakajima, D., Yoshimura, R., Endo, Y., and Ohara, O. (2002). MEGF1/fat2 proteins containing extraordinarily large extracellular domains are localized to thin parallel fibers of cerebellar granule cells. Mol. Cell. Neurosci. 20, 563-578.

Nanao, M. H., Green, T., SternBach, Y., Heinemann, S. F., and Choe, S. (2005). Structure of the kainite receptor subunit GluR6 agonist-binding domain complexed with domoic acid. Proc. Natl. Acad. Sci. U.S.A. 102, 1708-1713.

Pulido, R., Serra-Pagès, C., Tang, M., and Streuli, M. (1995). The LAR/PTP $\delta / P T P \sigma$ subfamily of transmembrane protein-tyrosinephosphatases: multiple human LAR, PTP $\delta$, and PTP $\sigma$ isoforms are expressed in a tissue-specific manner and associate with the LAR-interacting protein LIP.1. Proc. Natl. Acad. Sci. U.S.A. 92, 11686-11690.

Roche, K. W., Ly, C. D., Petralia, R. S., Wang, Y. X., McGee, A. W., Bredt, D. S., et al. (1999). Postsynaptic density- 93 interacts with the $\delta 2$ glutamate receptor subunit at parallel fiber synapses. J. Neurosci. 19, 3926-3934.

Rosenmund, C., Stern-Bach, Y., and Stevens, C. F. (1998). The tetrameric structure of a glutamate receptor channel. Science 280, 1596-1599.

Scheiffele, P., Fan, J., Choih, J., Fetter, R., and Serafini, T. (2000). Neuroligin expressed in nonneuronal cells triggers presynaptic development in contacting axons. Cell 101, 657-669.

Schorge, S., and Colquhoun, D. (2003). Studies of NMDA receptor function and stoichiometry with truncated and tandem subunits. J. Neurosci. 23, 1151-1158.

Shen, K., and Scheiffele, P. (2010). Genetics and cell biology of building specific synaptic connectivity.
Annu. Rev. Neurosci. 33, 473-507.

Siddiqui, T. J., and Craig, A. M (2011). Synaptic organizing complexes. Curr. Opin. Neurobiol. 21 132-143.

Sobolevsky, A. I., Rosconi, M. P., and Gouaux, E. (2009). X-ray structure, symmetry and mechanism of an AMPA-subtype glutamate receptor. Nature 462, 745-756.

Sobolevsky, A. I., Yelshansky, M. V., and Wollmuth, L. P. (2004). The outer pore of the glutamate receptor channel has 2-fold rotational symmetry. Neuron 41, 367-378.

Südhof, T. C. (2008). Neuroligins and neurexins link synaptic function to cognitive disease. Nature 455, 903-911.

Sun, Y., Olson, R., Horning, M., Armstrong, N., Mayer, M., and Gouaux, E. (2002). Mechanism of glutamate receptor desensitization. Nature 417, 245-253.

Takayama, C., Nakagawa, S., Watanabe, M., Mishina, M., and Inoue, Y. (1996). Developmental changes in expression and distribution of the glutamate receptor channel $\delta 2$ subunit according to the Purkinje cell maturation. Brain Res. Dev. Brain Res. 92, 147-155.

Takeuchi, T., Miyazaki, T., Watanabe, M., Mori, H., Sakimura, K., and Mishina, M. (2005). Control of synaptic connection by glutamate receptor $\delta 2$ in the adult cerebellum. J. Neurosci. 25 2146-2156.

Takeuchi, T., Ohtsuki, G., Yoshida, T., Fukaya, M., Wainai, T., Yamashita, M., et al. (2008). Enhancement of both long-term depression induction and optokinetic response adaptation in mice lacking delphilin. PLOS ONE 3:e2297. doi: 10.1371/journal.pone.0002297

Tichelaar, W., Safferling, M., Keinänen, K., Stark, H., and Madden, D R. (2004). The three-dimensional structure of an ionotropic glutamate receptor reveals a dimer-of-dimers assembly. J. Mol. Biol. 344, 435-442.

Uemura, T., Mori, H., and Mishina, M. (2004). Direct interaction of GluR 82 with Shank scaffold proteins in cerebellar Purkinje cells. Mol. Cell. Neurosci. 26, 330-341.

Uemura, T., Kakizawa, S., Yamasaki, M., Sakimura, K., Watanabe, M. Iino, M., et al. (2007). Regulation of long-term depression and climbing fiber territory by glutamate receptor $\delta 2$ at parallel fiber synapses through its C-terminal domain in cerebellar Purkinje cells. J. Neurosci. 27, 12096-12108.
Uemura, T., and Mishina, M. (2008). The amino-terminal domain of glutamate receptor $\delta 2$ triggers presynaptic differentiation. Biochem. Biophys. Res. Commun. 377, 1315-1319.

Uemura, T., Lee, S. J., Yasumura, M., Takeuchi, T., Yoshida, T., Ra, M., et al. (2010). Trans-Synaptic interaction of GluR $\delta 2$ and neurexin through Cbln 1 mediates synapse formation in the cerebellum. Cell 141, 1068-1079.

Urakubo, T., Tominaga-Yoshino, K., and Ogura, A. (2003). Non-synaptic exocytosis enhanced in rat cerebellar granule neurons cultured under survival-promoting conditions. Neurosci. Res. 45, 429-436.

Varoqueaux, F., Aramuni, G., Rawson, R. L., Mohrmann, R., Missler, M., Gottmann, K., et al. (2006). Neuroligins determine synapse maturation and function. Neuron 51, 741-754.

Waites, C. L., Craig, A. M., and Garner, C. C. (2005). Mechanisms of vertebrate synaptogenesis. Annu. Rev. Neurosci. 28, 251-274.

Weston, M. C., Schuck, P., Ghosal, A., Rosenmund, C., and Mayer, M. L. (2006). Conformational restriction blocks glutamate receptor desensitization. Nat. Struct. Mol. Biol. 13, 1120-1127.

Williams, M. E., de Wit, J., and Ghosh, A. (2010). Molecular mechanisms of synaptic specificity in developing neural circuits. Neuron 68, 9-18.

Yamasaki, M., Miyazaki, T., Azechi, H., Abe, M., Natsume, R., Hagiwara, T., et al. (2011). Glutamate receptor $\delta 2$ is essential for input pathwaydependent regulation of synaptic AMPAR contens in cerebellar Purkinje cells. J. Neurosci. 31, 3362-3374.

Yamazaki, M., Araki, K., Shibata, A., and Mishina, M. (1992). Molecular cloning of a cDNA encoding a novel member of the mouse glutamate receptor channel family. Biochem. Biophys. Res. Commun. 183, 886-892.

Yap, C. C., Muto, Y., Kishida, H., Hashikawa, T., and Yano, R. (2003). PKC regulates the $\delta 2$ glutamate receptor interaction with S-SCAM/MAGI-2 protein. Biochem. Biophys. Res. Commun. 301, 1122-1128.

Yawata, S., Tsuchida, H., Kengaku, M., and Hirano, T. (2006). Membraneproximal region of glutamate receptor $\delta 2$ subunit is critical for long-term depression and interaction with protein interacting 
with C kinase 1 in a cerebellar Purkinje neuron. J. Neurosci. 26, 3626-3633.

Yue, Z., Horton, A., Bravin, M., DeJager, P. L., Selimi, F., and Heintz, N. (2002). A novel protein complex linking the $\delta 2$ glutamate receptor and autophagy: implications for neurodegeneration in lurcher mice. Neuron 35, 921-933.

Ziv, N. E., and Garner, C. C. (2004). Cellular and molecular mechanisms of presynaptic assembly. Nat. Rev. Neurosci. 5, 385-399.

Zuo, J., De Jager, P. L., Takahashi, K. A., Jiang, W., Linden, D. J., and Heintz, N. (1997). Neurodegeneration in lurcher mice caused by mutation in $\$ 2$ glutamate receptor gene. Nature $388,769-773$.

Conflict of Interest Statement: The authors declare that the research was conducted in the absence of any commercial or financial relationships that could be construed as a potential conflict of interest.

Received: 30 August 2012; accepted: 02 November 2012; published online: 23 November 2012.

Citation: Mishina $M$, Uemura T Yasumura $M$ and Yoshida T (2012) Molecular mechanism of parallel fiberPurkinje cell synapse formation. Front.
Neural Circuits 6:90. doi: 10.3389/fncir 2012.00090

Copyright (c) 2012 Mishina, Uemura, Yasumura and Yoshida. This is an openaccess article distributed under the terms of the Creative Commons Attribution License, which permits use, distribution and reproduction in other forums, provided the original authors and source are credited and subject to any copyright notices concerning any third-party graphics etc. 